\title{
A Study of the Application Strategies of Mobile Social Media-the LINE Official Account in University and College Marketing and Public Relations
}

\author{
Chi-Hu Tien, Chia-Sung Yen \\ Hungkuang University, Taichung, Taiwan
}

\begin{abstract}
A 2014 survey indicated that $77.8 \%$ of Taiwanese individuals over 12 years of age were mobile Internet users, and that the most commonly used app was distributed by LINE Corporation (LINE). Given the increasing popularity of mobile Internet devices, as evidenced by the widespread use of smart phones, the dissemination of information mainly through traditional media is no longer adequate. Nevertheless, the marketing and public relations strategies of Taiwanese universities and colleges still largely rely on traditional media, venturing online only to establish official websites, and investing very little in mobile social media. This study has adopted a case study approach by focusing on Hungkuang University, which has set up a LINE Official Account that has attracted more "LINE friends" than any other university or college account in Taiwan. By analyzing and discussing this case study, we hope to present information on both the benefits that universities and colleges can derive-and the operational strategies they can employ—by using LINE Official Accounts as part of their marketing and public relations strategies. These findings will provide reliable strategic guidance on marketing and public relations practices in universities and colleges. This study introduces the LINE Official Account as a new option that works differently from traditional media. It is a new and effective mobile marketing tool for school and university marketing and public relations strategies. The seven key strengths of a LINE Official Account for educational marketing and public relations are as follows: (1) It uses the latest mobile Internet apps to establish an organizational image of high-quality service; (2) It employs a large number of media editors to provide efficient and comprehensive information services; (3) It reinforces marketing communications through both one-to-many and one-to-one approaches; (4) It uses mobile Internet social events to increase a sense of participation among friends; (5) It reinforces the horizontal connections between different units and disseminates information to maintain internal and external relationships; (6) It constantly recruits new friends through physical enrolment activities and advertising; and (7) It provides crisis management by taking advantage of widespread mobile Internet use.
\end{abstract}

Keywords: LINE Official Account, university marketing, public relations strategies

\section{Introduction}

Social media help to fulfill the human need for interaction. By transforming traditional "one-to-many" into "many-to-many" communications via social media. For this reason, social media content can be characterized

Chi Hu Tien, assistant professor, Department of Cultural and Creative Industries, Hungkuang University.

Chia-Sung Yen, assistant professor, Department of Cultural and Creative Industries, Hungkuang University. 
as "user-generated" content (UGC) (Onmedia, 2009). According to a 2015 "Survey on Broadband Internet Usage in Taiwan" conducted by the Taiwan Network Information Center (TWNIC), the percentage of Internet users in the Taiwanese population increased from $75.6 \%$ in 2014 to $80.3 \%$ in 2015. A total of 16,372,581 Taiwanese individuals over 12 years old (78.2\%) have Internet experience. The majority of people interviewed were using $3 \mathrm{G}$ or $3.5 \mathrm{G}$, while $94 \%$ use smart phones to access the Internet.

The smart phone application program, LINE, developed by Naver Corporation (NHN) Japan Corporation, was launched in June 2011. In 2013, the NHN Japan Corporation announced that the number of global registered users of LINE officially exceeded 300 million and was likely to continue to increase; in Taiwan, the number of registered users has reached 17 million. Among smart phone apps, the 10 most commonly used apps include four that involve instant messaging software: LINE (1st), Whats App (4th), Facebook Messenger (8th), and WeChat (10th) (TWNIC, 2015). LINE is the most popular instant messaging software in Taiwan, especially among young people. The penetration rate of LINE on smart phones is $92 \%$, far higher than any other messaging software (INSIGHTXPLORER, 2014).

Mobile social media are currently the best tools for such interactions, and LINE has been rated the most popular tool in Taiwan. We selected Hungkuang University as our case study and the university has accumulated more than 7,000 university fans in Taiwan.

This study has focused on two questions:

1. What are the differences between a LINE Official Account and traditional tools for marketing and public relations?

2. Are marketing and public relations strategies employed by universities and colleges?

\section{Literature Review}

Armstrong and Kolter (2000) have defined relationship marketing as the process of creating, maintaining, and enhancing the relationship with customers and other stakeholders, in order to obtain customer satisfaction and loyalty in the long term.

According to Cheng (2014), relationship marketing is gradually attracting more attention for the following reasons. Firstly, the cost of maintaining regular customers is far less than the cost of acquiring new customers. Secondly, mass media is expensive to use, and its impact is difficult to measure. Thirdly, customers and service-providers interact more closely than ever before. Fourthly, advances in information technology have contributed to the implementation of new approaches to relationship marketing. Jao (2005) found that four factors were needed to achieve optimal relationship marketing: (1) services that offered constant innovation; (2) comprehensive and diverse channels for services; (3) comprehensive management of customer relations; and (4) continuous relationship marketing. Hagel and Armstrong (1997) have defined the following four types of participation among virtual community members based on degree and participation value.

1. Browser: New community members, who often browse communities casually;

2. Lurker: Members who spend more time in the community than browsers, but do not actively make content contributions as contributors do;

3. Contributor: After a period of time, browsers who chose to stay are likely to become contributors who contribute content to the community actively and passionately. They are the second most highly valued members in a community; 
4. Shopper: Active members who actively participate in communities, and also purchase products and services. They have the highest value of all members.

"Public relations (PR)" are planned communications designed to achieve mutual understanding between an organization and the general public. The ideal public relations model is characterized by two-way, dialogic communications that create a communication environment of truth, tolerance, mutual trust, equality, and support (Grunig, 2001).

Most previous studies have been based on the principle of dialogic communications proposed by Kent and Taylor (1998), which has been widely applied to public relations strategies on the Internet and recognized as a basis for establishing more effective communication strategies. Zhang, Craciuna, and Shin (2010) have argued that companies ought to use entertaining content to make their brands appealing and to attract the attention of their target audience. Kelleher and Miller (2006) discovered that social media was the best way to build a relationship between an organization and the public. Lovejoy and Saxton (2012) discovered that tweets could be grouped into three categories: information, community, and action. In contrast to traditional websites, Twitter established relationships with stakeholders through dialogic and community-building approaches. Furthermore, Wright and Hinson (2009) have pointed out that most public relations professionals believe that developing the relationship between organizations and their target audiences through social media is cost effective. However, finding optimal ways to integrate social media functions into organizational communication strategies is an area that needs further research (Alikilic \& Atabek, 2012).

\section{Research Method}

This study has adopted a case study approach. In June 2015, LINE announcements were used to invite members to participate in an online questionnaire survey; 1,470 individuals participated. In addition, the researchers designed an open-ended questionnaire and (between May and June 2015) interviewed six individuals, including the Hungkuang University Public Relations Director and administrative officials responsible for the university's strategy.

\section{Research Results}

1. The LINE Official Account is a new and effective mobile marketing tool for school and university marketing and public relations strategies.

For marketing professionals, therefore, finding ways to market an Official Account, invite new visitors to become active fans, and achieve acceptance for messages and marketed products have become key focal points. The Hungkuang University Director of Public Relations commented that, "LINE is an instant communication medium; when fans receive messages, they can immediately click on them and begin interactions."

2. A LINE Official Account is a new option that differs from traditional marketing and public relations tools. As for goals, when organizations use news agents and broadcasting PR models, they tend to post information that benefits themselves.

LINE Official Accounts begin by adopting a "passive approach" to advertising (i.e., waiting for consumers to voluntarily add them as friends). After consumers have become friends, these accounts employ an "interactive approach" (i.e., companies disseminate information and consumers can connect to their websites) to establish relationships with consumers. 
3. A LINE Official Account enables schools and universities to use the following seven marketing and public relations strategies:

(1) Using the latest mobile Internet apps to give themselves a reputation for (and image related to) high-quality service.

(2) Employing a large number of media editors to provide efficient and comprehensive information services. When there is any problem involving university affairs, these editors must try to respond within 24 hours; in case of emergency, the university will immediately send someone to resolve it. It is not surprising that Hungkuang University is ranked top among all universities and colleges in Taiwan for its number of users (see Figure 1).

(3) Applying one-to-many or one-to-one approaches to reinforce marketing communications. Open one-to-one dialogues are akin to having exclusive mobile secretaries responsible for students. According to the online survey, $72 \%$ of respondents gave the editors the highest possible rating of " 5 stars" (see Figure 2).

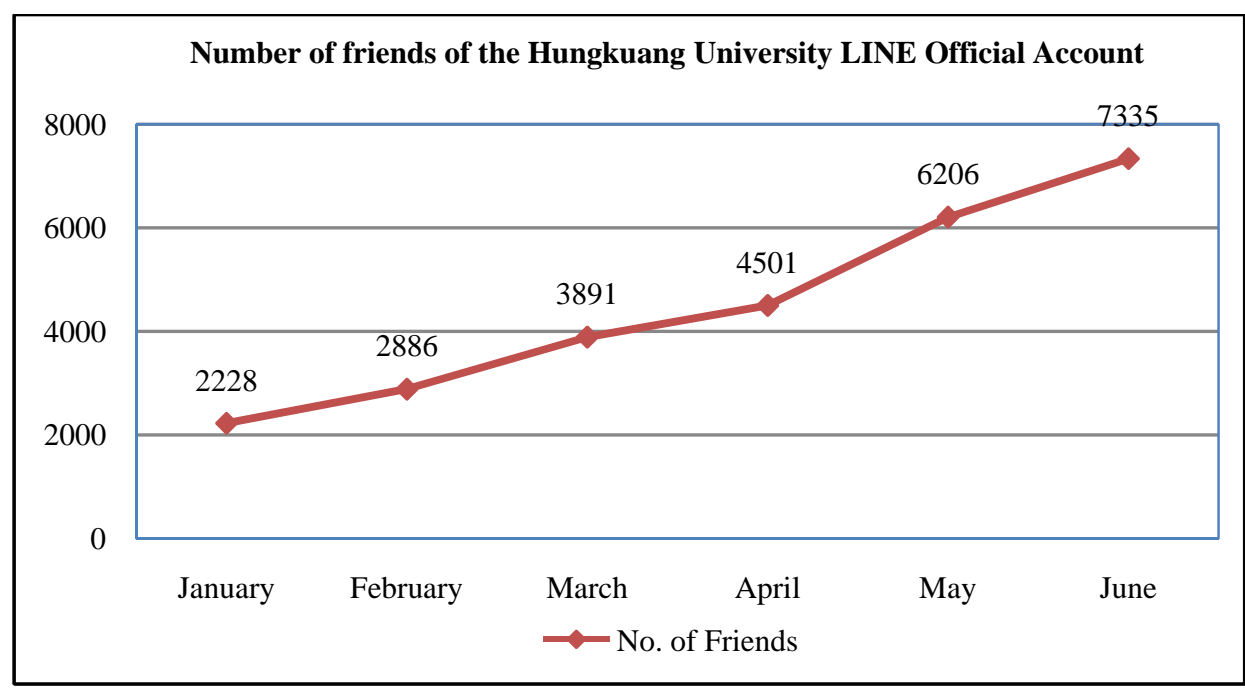

Figure 1. The growing number of friends of the Hungkuang University LINE Official Account.

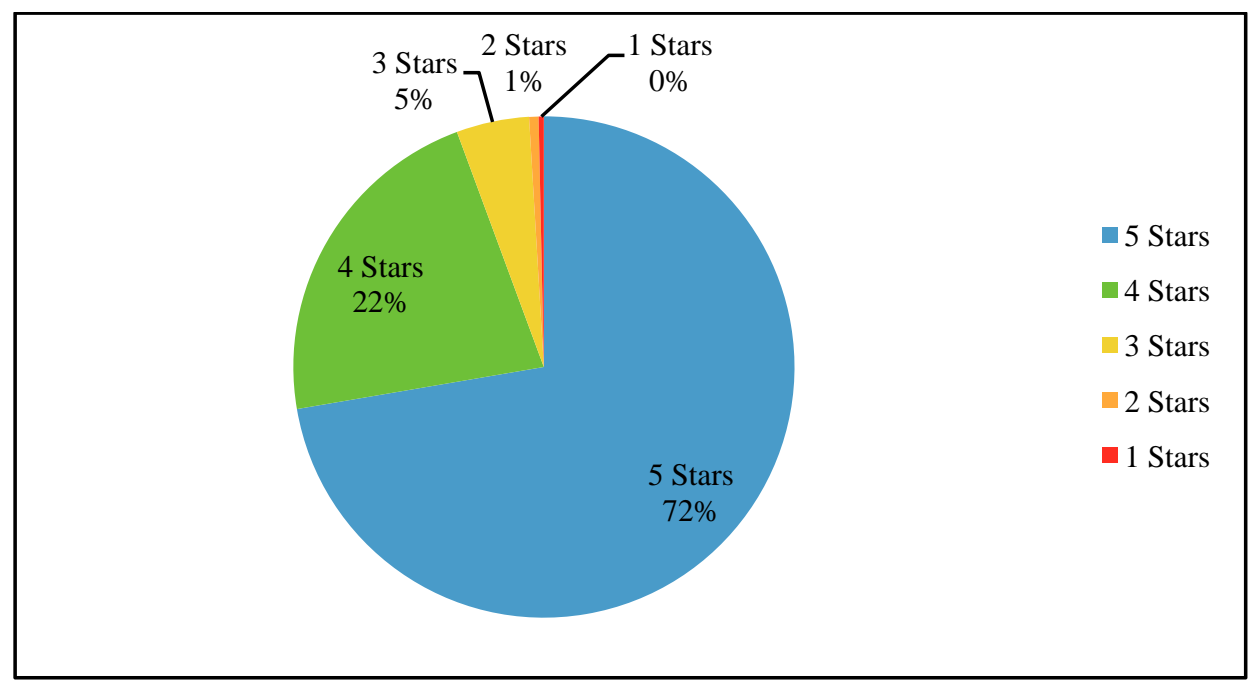

Figure 2. Ratings for editor services. 
(4) Using social events on the mobile Internet to increase a sense of participation among friends. Online survey shows that the most helpful information involves announcements about sporadic lottery draw activities posted on the Official Account (see Figure 3).

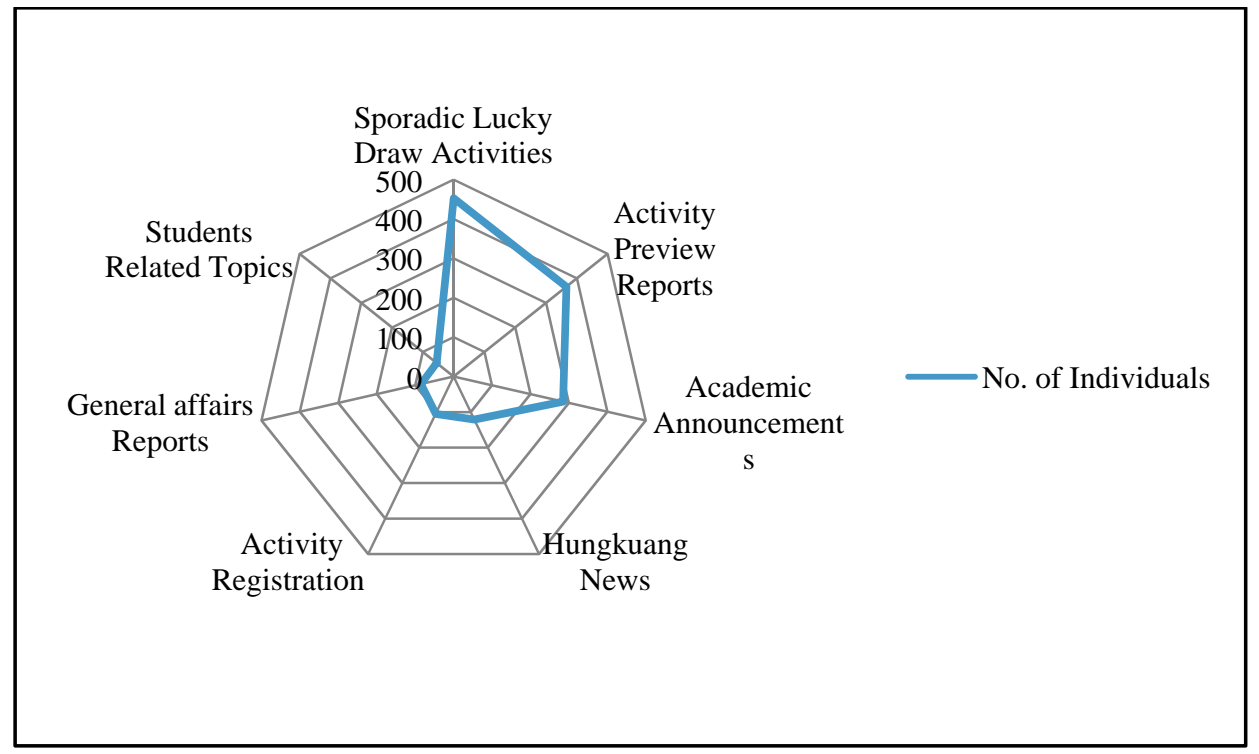

Figure 3. Friends' favorite types of information.

(5) Reinforcing the horizontal connections between different units and publicizing information to maintain internal and external relations. The LINE Official Account has been able to achieve timely, two-way, and diverse interactions.

(6) Constantly recruiting friends through physical enrolment activities and advertising. Organizations can adopt approaches, such as actively sending messages, regularly distributing e-newsletters and media reports, and inviting people to attend education exhibitions to encourage the target audience to obtain information about the school or university, and to join as friends (see Figure 4).

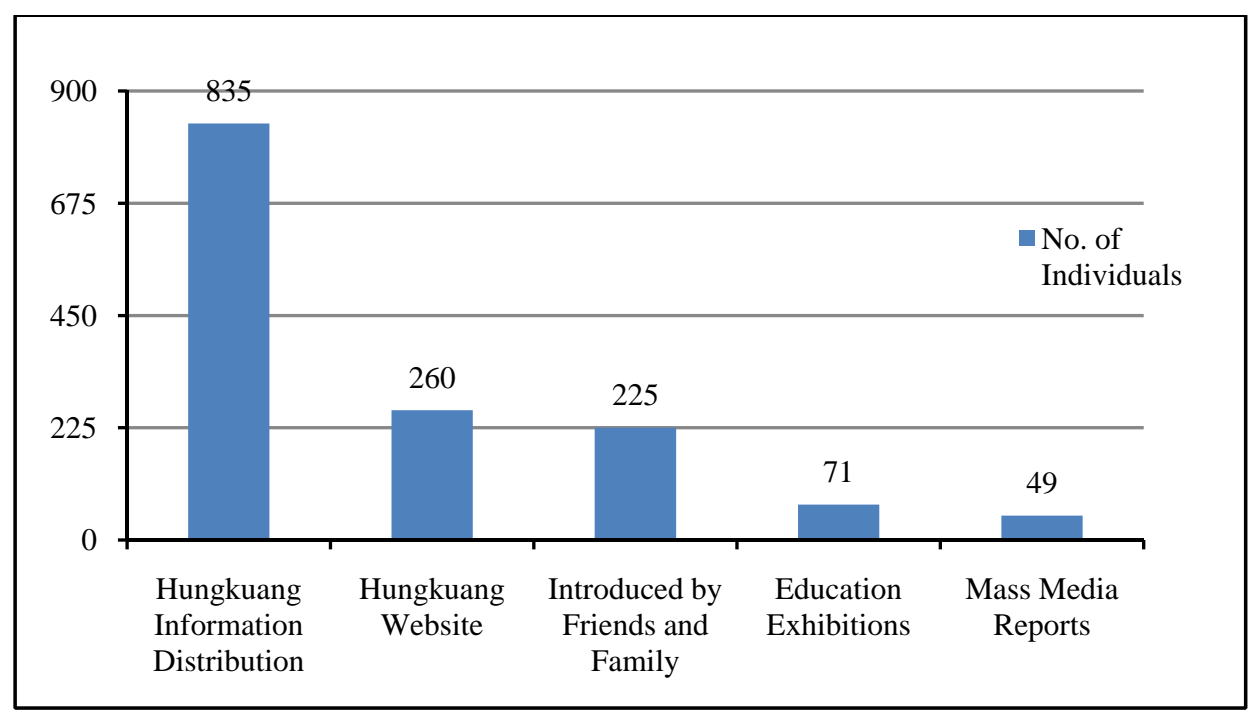

Figure 4. Information channels for those added as friends. 
(7) Conducting crisis management by taking advantage of the ubiquity of the mobile Internet. The university used LINE to notify students that they should immediately change classroom; this was done to avoid confusion when the students arrived at school. Many students joked about it, saying, "We can not find an excuse for not attending school.”

4. The key to success lay in the proactive approach of the LINE Official Account operation team and the effectiveness of the feedback mechanism. The individuals in charge of the response window are all known anonymously as "editors." The organizational framework is illustrated by Figure 5 below:

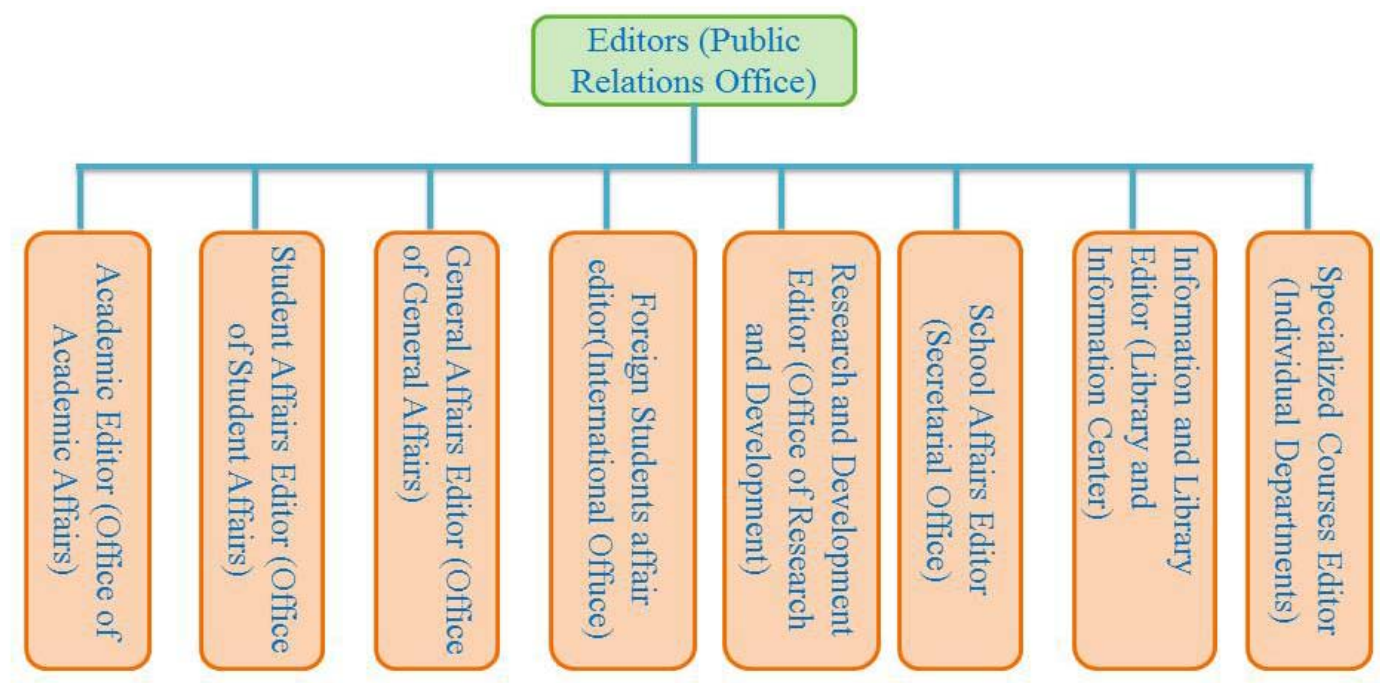

Figure 5. Organizational framework of Hungkuang University’s LINE Official Account management.

All editors can simultaneously view a question from any friend via the back-end management platform. There are 22 editors in total, around 7 of them are proactive, answering questions every day (see Figure 6).

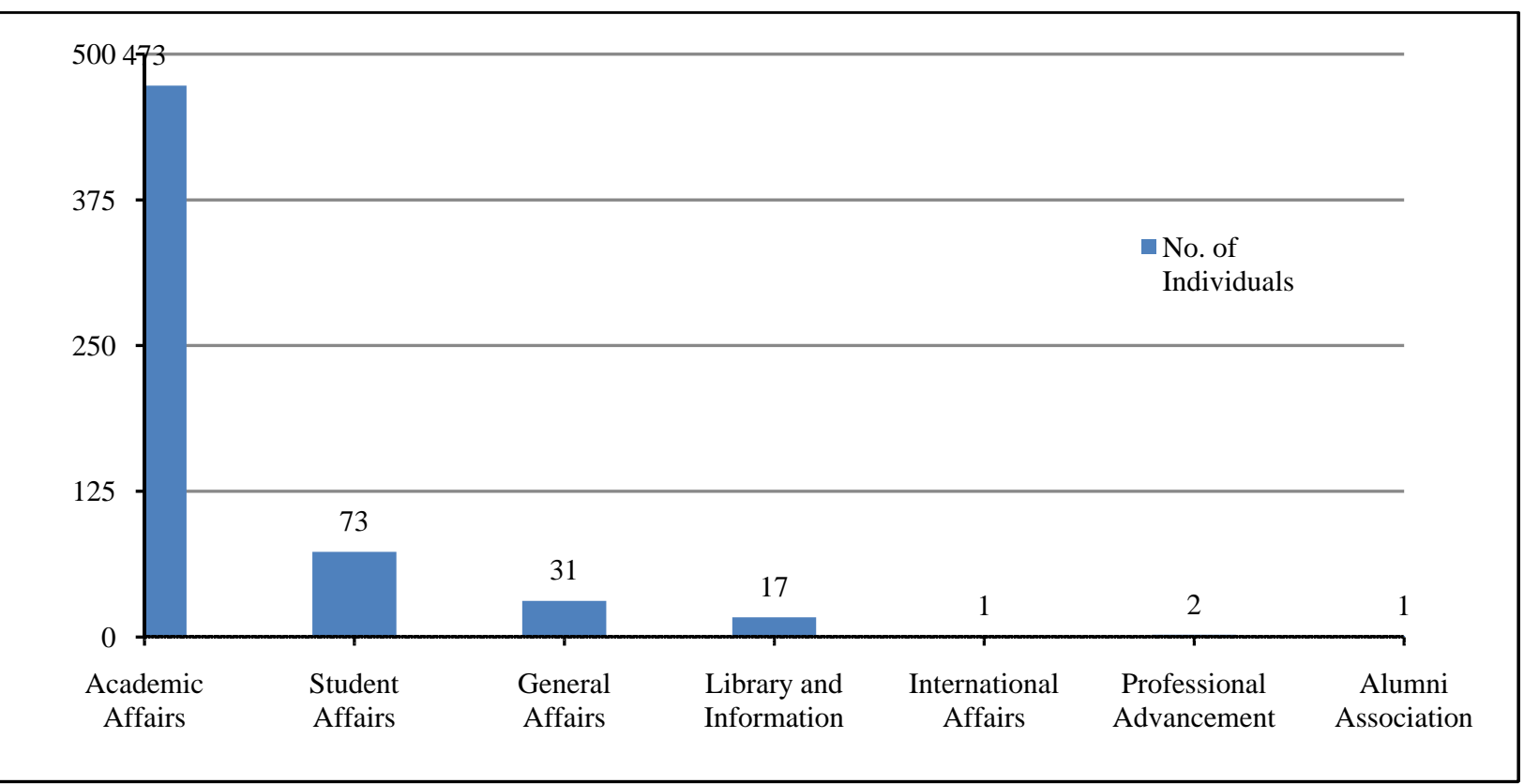

Table 6. Categories of questions asked by friends of the Hungkuang University LINE Official. 


\section{Discussion and Conclusion}

This study shows that LINE Official Accounts are indeed effective tools for school and university marketing and public relations. The operation strategies developed by one institution can also be transferred to others. The first concerns costs and benefits. In terms of cost analysis, the tools used in the past for public relations communications, such as traditional media, the telephone, and marketing activities require more manpower and expensive resources to achieve timely and interactive communications. Second, in order to keep a LINE Official Account functioning efficiently, a substantial amount of professional labor is required. The third issue relates to the education, training, recognition, and discipline of personnel. Behind the scenes, LINE Official Accounts personnel should have expertise in professional fields and proficiency in using apps; they should also be able to use terms and expressions that young people use to communicate with friends. Lastly, LINE Official Accounts can function only as a supplementary mechanism, and will never replace formal communication channels. Outside the group of friends with interactions, LINE does not make it possible to obtain much information about friends who have joined, but do not ask or respond to questions.

Furthermore, this new tool has untapped potential for development; by incorporating the commercial circles that surround a particular university or school, a LINE Official Account can extend its circle of influence, uncover revenue resources, develop downloaded images, and generate non-business income. For this reason, universities that have invested in managing LINE Official Accounts are encouraged to continue developing this resource, while those that have not are recommended to rapidly evaluate the potential benefits and follow suit.

\section{References}

Alikilic, O., \& Atabek, U. (2012). Social media adoption among Turkish public relations professionals: A survey of practitioners. Public Relations Review, 38(1), 56-63.

Armstrong, G., \& Kotler, P. (2000). Marketing: An introduction (5th ed.). New Jersey: Prentice Hall.

Cheng, K. F. (2014). Services marketing and management: Quality enhancement and value creation. Taipei: Future Culture Management Company. (in Chinese)

Grunig, J. E. (2001). Two-way symmetrical public relations: Past, present, and future. Handbook of Public Relations, 11, 30.

Hagel, J., \& Armstrong, A. G. (1997). Net gain: Expanding markets through virtual communities. Boston, M.A.: Harvard Business School Press.

Heath, R. L. (Ed.). Handbook of public relations (pp. 11-30). Thousand Oaks, C.A.: Sage.

INSIGHTXPLORER. (2014). Retrieved from https://order.csn.com.tw/downloads/lineintroductionoastickers201405272014-h2140619112634-phpapp01.pdf (in Chinese)

Jao, H. P. (2005). A study on relationship marketing and loyalty—An example of eastern home shopping (EHS). Research Institute of the Department of Public Relations and Advertising, Shih Hsin University. (in Chinese)

Kent, M. L., \& Taylor, M. (1998). Building dialogic relationships through the World Wide Web. Public Relations Review, 24(3), 321-334.

Kelleher, T., \& Miller, B. M. (2006). Organizational blogs and the human voice: Relational strategies and relational outcomes. Journal of Computer-Mediated Communication, 11 (2), 395-414.

Lai, Y. Y. (2011). Internet public relations strategies of a Facebook fan page: A case study of "try it, request a free trial fan page" (Master's thesis, Research Institute of the Department of Public Relations and Advertising, Shih Hsin University). (in Chinese)

Lovejoy, K.,Waters, R. D., \& Saxton, G. D. (2012). Engaging stakeholders through Twitter: How nonprofit organizations are getting more out of 140 characters or less. Public Relations Review, 38, 313-318.

Onmedia. (2009). Social media marketing. Retrieved from http://www.taaa.org.tw/userfiles/Onmedia\%20Sept\%202009.pdf (in Chinese) 
Sun, H. H. (2000). Corporate public relations in the Internet era-Theoretical reconstruction of Grunig's model. The Journal of Advertising Research, 15, 1-24. (in Chinese)

Sun, H. H. (2004). Assessing the effectiveness of web-based public relations: A study of Taiwan's top 500 corporations in the service industry. The Journal of Advertising Research, 21, 1-28. (in Chinese)

Sun, H. H. (2009). Public relations: Theory, strategy, and case studies. Taipei: Cheng Chung. (in Chinese)

Taiwan Network Information Center (TWNIC). (2015). Survey on wireless Internet usage in Taiwan. Retrieved from http://www.twnic.net.tw/NEWS4/137.pdf (in Chinese)

TWNIC. (2015). Survey on usage of wireless Internet in Taiwan. Retrieved from http://www.twnic.net.tw/download/200307/ 20140109e.pdf (in Chinese)

Wright, D. K., \& Hinson, M. D. (2009). An analysis of the increasing impact of social and other new media on public relations practice. International Public Relations Research Conference. Miami, F.L. Retrieved from http://www.instituteforpr.org/ research_single/wright_hinson_social_media_miami

Zhang, J. Q., Craciuna, G., \& Shin, D. (2010). When does electronic word of mouth matter? A study of consumer product reviews. Journal of Business Research, 63(12), 1336-1341. 